5. Bộ Y tế (2016). Hướng dẫn chẩn đoán và điều trị các bệnh cơ xương khớp. Nhà xuất bản Y học, Hà Nội.

6. Bô̂ Y tế (2020). Hướng dẫn chẩn đoán và điều trị bểnh theo $Y$ học cổ truyên, kết hợp $Y$ học cổ truyền với $Y$ học hiện đại. Nhà xuất bản $Y$ học, Hà Nội.
7. Bạc Trí Vân (2012). Liệu pháp Phúc châm. Nhà xuất bản $Y$ dược cổ truyền Trung Quốc.

8. Ha Xung, Hà Hiểu Đơn (2021). So sánh hiệu quả của phúc châm với châm cứu truyền thống trong điêuu trị chứng đau đâuu do thoái hoá cột sống cổ. Y dược hướng thôn Trung Quốc.

\title{
LIÊN QUAN GIỮA DẤU HIỂU T ÂM Ở CHUYỂN ĐẠO AVL TRÊN ĐIỆN TÂM ĐỒ VỚI TỔN THƯƠ'NG ĐộNG MACH LIÊंN THẤT TRƯỚC Ở BÊ̂NH NHÂN HộI CHỨNG VÀNH CẤP
}

\section{TÓM TẮT}

Điên tâm đồ là một công cu đơn giản, có vai trò quan trọng trong chẩn đoán xác định, chẩn đoán định khu, cũng như tiên lương và theo dõi điều tri bểnh nhân hội chứng mạch vành cấp. Giá trị của dấu hiệu T âm ở chuyển đạo aVL trong dự đoán tổn thương đoạn giữa động mach liên thẩt trước ở bệnh nhân hội chứng vành cẩp vẫn chưa được nhấn mạnh hoắc chưa được công nhận. Mục tiêu: Tìm hiểu mối liên quan giữa dấu hiệu $\mathrm{T}$ âm ở chuyển đạo $\mathrm{aVL}$ trên điên tâm đồ với tổn thương đoan giữa động mạch liên thất trướ cở bệnh nhân hội chứng vành cấp. Đối tượng và phưởng pháp nghiên cứu: Mô tả cắt ngang 401người bệnhHội chứng vành cấplần đầu (bao gồm214 bênh nhần NMCT có ST chênh lên và 187 bệnh nhân NMCT không có ST chênh lên), được chụp ĐMV qua da tại Viện Tim mạch Việt Nam từ tháng 8 năm 2020 đến tháng 8 năm 2021. Kết cục chính là tổn thương hep MLAD $\geq 70 \%$ và MLAD là ĐMV thủ pham. Kết quả nghiên cứu: Ở nhóm NMCT cấp có ST chênh lên dấu hiệu $T$ âm ở chuyển đạo aVL là biến duy nhất dự đoán có ý nghĩa tổn thương MLAD (OR = $2,17, \mathrm{CI} 95 \%=1,17-3,97, \mathrm{p}<0,05)$. Dấu hiệu T âm ở chuyển đạo $\mathrm{aVL}$ có giá trị dự báo tổn thương/ thủ pham là đoạn giữa động mạch liên thất trước với độ nhậy, giá trị dự báo dương tính lần lượt là $64,5 \%$, $71,1 \%$ và $78,7 \%, 50,4 \%$; tuy nhiên độ đặc hiệu thấp $54,2 \%$ và $49,2 \%$. Dấu hiêu $T$ âm đơn đổc ở chuyển đạo aVL có giá trị dự báo tổn thương MLAD với độ đặc hiêu cao là $96,6 \%$. Ớ phân nhóm NMCT thành trước dẩu hiệu $\mathrm{T}$ âm ở chuyển đạo $\mathrm{aVL}$ có giá trị dự báo tổn thương/ thủ phạm là đoạn giữa động mạch liên thất trước với độ nhậy, giá trị dự báo dương tính lần lượt là70,2\%; $71,1 \%$ và $78,5 \% ; 68,8 \%$. Ở phân nhóm NMCT thành sau không rõ mối liên quan giữa dấu hiệu $\mathrm{T}$ âm ở chuyển đạo $\mathrm{aVL}$ với tổn thương MLAD. Kết luận: Ở bệnh nhân NMCT có ST chênh lên, dấu hiệu T âm ở chuyển đạo $\mathrm{aVL}$ trên điện tâm đồ có liên quan và có giá trị dự báo vị trí tổn thương hoặc thủ phạm là

\footnotetext{
${ }^{1}$ Bệnh viện 198-Bộ Công An

${ }^{2}$ Bềnh viền Bach Mai

Chịu trách nhiệm chính: Đức Thị Hoa

Email: ducthihoa@gmail.com

Ngày nhận bài: 16.8 .2021

Ngày phản biên khoa hoc: 11.10.2021

Ngày duyệt bài: 19.10.2021
}

\section{Đức Thị Hoa ${ }^{1}$, Nguyễn Thị Bạch Yến ${ }^{2}$}

MLAD. Ở nhóm NMCT không ST chênh chưa thây liên quan giữa dấu hiệu $\mathrm{T}$ âm ở chuyển đạo $\mathrm{aVL}$ với vị trí tổn thương hoăc thủ pham là MLAD.

Tư khóa: Hội chứng mạch vành cấp, Điện tâm đồ, Sóng T âm, Đoạn giữa động mạch liên thất trước.

\section{SUMMARY \\ RELATIONSHIP BETWEEN T WAVE INVERSION IN LEAD AVL ONELECTROCARDIOGRAM AND LEFT ANTERIOR DESCENDING ARTERY LESIONS IN ACUTE CORONARY SYNDROME}

The ECG is a basictool that plays an important role in the definitive diagnosis, predective lesions location, as well as the prognosis and monitoring of patients with acute coronary syndrome( ACS). Value of electrocardiographic $\mathrm{T}$ wave inversion in lead $\mathrm{aVL}$ for mid-segment left anterior descending (MLAD) lesions in patients with ACShas not been emphasized or well recognized. Objective: To study the relationship between $\mathrm{T}$ wave inversion in lead $\mathrm{aVL}$ and midsegment left anterior descending (MLAD) lesions in patients with acute coronary syndrome (ACS). Method: We performed a cross- sectional study include 401 patients with acute coronary syndromefor the first time (214 STEMI, 187 NSTEMI), who underwent PCI at The Vietnam Heart Institutefrom August 2020 to August 2021. The primary outcome was MLAD lesion $\geq 70 \%$ and MLAD lesion as the culprit. Results: In STEMIgroup,T wave inversion in aVL was found to be the only ECG variable significantly predicting mid segment left anterior descending artery (MLAD) lesions (OR=2,17, CI95\% $=1,17-3,97, p<0,05) . T$ wave inversion in lead $\mathrm{aVL}$ had a sensitivity of $64,5 \% ; 71,7 \%$, positive predictive value of $78,1 \%$; $50 \%$ for predicting MLAD lesions/MLAD lesion as the culprit.Isolated $\mathrm{T}$ wave inversion in lead aVL had a specificity of $92,8 \%$ for predicting MLAD lesions.In anterior STEMI, $T$ wave inversion in lead aVL had a sensitivity of $70,2 \%$; $71,1 \%$, positive predictive value of $78,5 \% ; 68,8 \%$ for predicting MLAD lesions/MLAD lesion as theculprit. In inferior STEMI, this relationship is not significantly different. Conclusions: In STEMI group, $T$ wave inversion in $\mathrm{aVL}$ on electrocardiogram has relationship and predictitive value in determination of whether location or culprit lesion was MLAD. However, in NSTEMI group that regconize un-relationship between 
$\mathrm{T}$ wave inversion in $\mathrm{aVL}$ and indentify of whether location or culprit lesion was MLAD.

Keywords: Acute coronary syndrome, electrocardiography, T wave inversion, left anterior descending lesion.

\section{I. ĐĂT VẤN ĐỀ}

Hội chứng mạch vành cấp là môt bênh cảnh cấp cứu nội khoa nguy hiểm tiên lượng nặng, tỷ lệ lệ tự vong cao cần được chẩn đoán và điều trị sớm. ở bệnh nhânbệnh động mạch vành cấp tính, điên tâm đồ đã khẳng định được vai trò trong việc định khu tổn thương các nhánh chính. Tuy nhiển việc định khu tổn thương là đoạn gần hay đoạn xa cũng rất cần thiết trong thực hành lâm sàng để giúp các thầy thuốc tiên lượng được trong việc can thiệp mạch. Vì vậy chúng tôi tiến hành nghiên cứu này nhằm mục tiêu: Tim hiểu mối liên quan giữa dấu hiệu $T$ ầm ở chuyển đạo aVL trên điện tâm đồ với tổn thương đoạn giửa động mạch liên thất trước ở bệnh nhân hội chứng vành cấp.

\section{II. ĐỐI TƯƠNG VÀ PHƯƠ'NG PHÁP NGHIÊN CỨU}

- Đối tượng nghiên cứu: Gồm 401 bệnh nhân được chẩn đoán hội chứng vành cấp lần đầu (bao gồm 214 bệnh nhân NMCT có ST chênh lên và 187 bệnh nhân NMCT không ST chênh lên), được chụp động mạch vành qua da tại Viện Tim mạch Việt Nam từ tháng 8 năm 2020 đến tháng 8 năm 2021. Loại trừ những bệnh nhân có bệnh gây ra biến đổi $T$ âm thứ phát trên ĐTĐ làm ảnh hưởng đến kết quả nghiên cứu
- Phương pháp nghiên cứu: Nghiên cứu tiền cứu, mô tả cắt ngang chùm ca bệnh.

Tất cả BNNC được ghi điện tâm đồ lúc vào viện, siêu âm Doppler tim, chụp động mạch vành qua da.

- Một số tiêu chuẩn sử dụng trong nghiên cứu

*Sóng $\mathrm{T}$ âm bệnh lý :sóng $\mathrm{T}$ âm $\geq 0,1 \mathrm{mV}$, nhọn, đối xứng (trừ $\mathrm{C} Đ \mathrm{aVR})^{1}$

Sóng $T$ âm ở aVL đơn độc: sóng $T$ âm chỉ ở chuyển đạo $\mathrm{aVL}$, bất kể $\mathrm{ST}$ chênh lên ở các chuyển đạo khác ${ }^{2}$.

* Đánh giá ĐMV thủ phạm :Là nhánh ĐMV có mức độ hẹp lớn nhât hoặc có hình ảnh huyết khối hoặc mảng xơ vữa không ổn định trong lòng ĐMV trên phim chụp ĐMV. Ở nhóm NMCT có ST chênh lên đối chiểu với hình ảnh điện tâm đồ ST chênh lên trong chẩn đoán định khu vùng nhồi máu cơ tim.

* Hẹp ĐMV có ý nghĩa $\geq 70 \%$ khẩu kính lòng mạch với 3 nhánh chính và $\geq 50 \%$ khẩu kính lòng mạch với thân chung ĐMV.

* Chia phân đoạn ĐMV: Động mạch liên thất trước chia làm 3 đoạn:

+ Đoạn gần: Từ chỗ chia đến trước nhánh chéo đầu tiên

+ Đoạn giữa: Từ nhánh chéo đầu tiên đến nhánh chéo thứ hai

+ Đoan xa: Từ sau nhánh chéo thứ hai.

-Xử lý số liệu: Số liệu thống kê được phân tích và xử lý bằng phần mềm SPSS 18.0

\section{KẾT QUẢ NGHIÊN CứU}

3.1Đặc điểm chung của nhóm đối tượng nghiên cứu

Bảng 1: Đăc điểm chung và các yếu tố nguy cơ của đôi tương nghiên cứu

\begin{tabular}{|c|c|c|c|}
\hline Thông số nghiên cứu & $\begin{array}{l}\text { NMCT cấp có ST chênh } \\
\text { lên }(n=214)\end{array}$ & $\begin{array}{l}\text { NMCT cấp không có } \\
\text { STchênh lên }(n=187)\end{array}$ & p \\
\hline Tuối trung bình & $67,95 \pm 11,44(36-93)$ & $69,13 \pm 10,82(40-91)$ & $>0,05$ \\
\hline Giới nam (n\%) & $149(69,63 \%)$ & $121(64,71 \%)$ & $>0,05$ \\
\hline Béo phì (n\%) & $35(16,36 \%)$ & $27(14,44 \%)$ & $>0,05$ \\
\hline Tăng huyết áp (n\%) & $146(68,22 \%)$ & $141(75,40 \%)$ & $>0,05$ \\
\hline Đái tháo đường (n\%) & $53(24,77 \%)$ & $53(28,34 \%)$ & $>0,05$ \\
\hline RLCH lipid ( $\mathrm{n} \%$ ) & $137(64,02 \%)$ & $134(71,66 \%)$ & $>0,05$ \\
\hline Nam hút thuốc lá (n\%) & $101(47,20 \%)$ & $96(51,34 \%)$ & $>0,05$ \\
\hline $\begin{array}{l}\text { Thời gian khởi phát đến } \\
\text { lúc nhập viện } \leq 12 \mathrm{~h}(\mathrm{n} \%)\end{array}$ & $94(43,93 \%)$ & $51(27,27 \%)$ & $<0,05$ \\
\hline
\end{tabular}

Bảng 2: Đặc điếm ĐMV tốn thương của nhóm đôî tượng nghiên cứu

\begin{tabular}{|c|c|c|c|c|}
\hline \multicolumn{2}{|c|}{ Thông sô nghiên cứu } & $\begin{array}{l}\text { NMCT có ST chênh } \\
\text { lên }(n=214)\end{array}$ & $\begin{array}{l}\text { NMCT không có ST } \\
\text { chênh lên }(n=187)\end{array}$ & $\mathbf{p}$ \\
\hline \multirow{4}{*}{ ĐMV tổn thương } & LAD (n\%) & $198(92,52 \%)$ & $170(90,91 \%)$ & $>0,05$ \\
\hline & RCA (n\%) & $123(57,48 \%)$ & $107(42,78 \%)$ & $>0,05$ \\
\hline & LCX $(n \%)$ & $89(41,59 \%)$ & $114(60,96 \%)$ & $<0,05$ \\
\hline & LM (n\%) & $17(7,94 \%)$ & $11(5,88 \%)$ & $>0,05$ \\
\hline Tốn thương theo & Đoạn gần (n\%) & $121(56,54 \%)$ & $104(55,61 \%)$ & $>0,05$ \\
\hline
\end{tabular}


VIETNAM MEDICAL JOURNAL N²0 - NOVEMBER - 2021

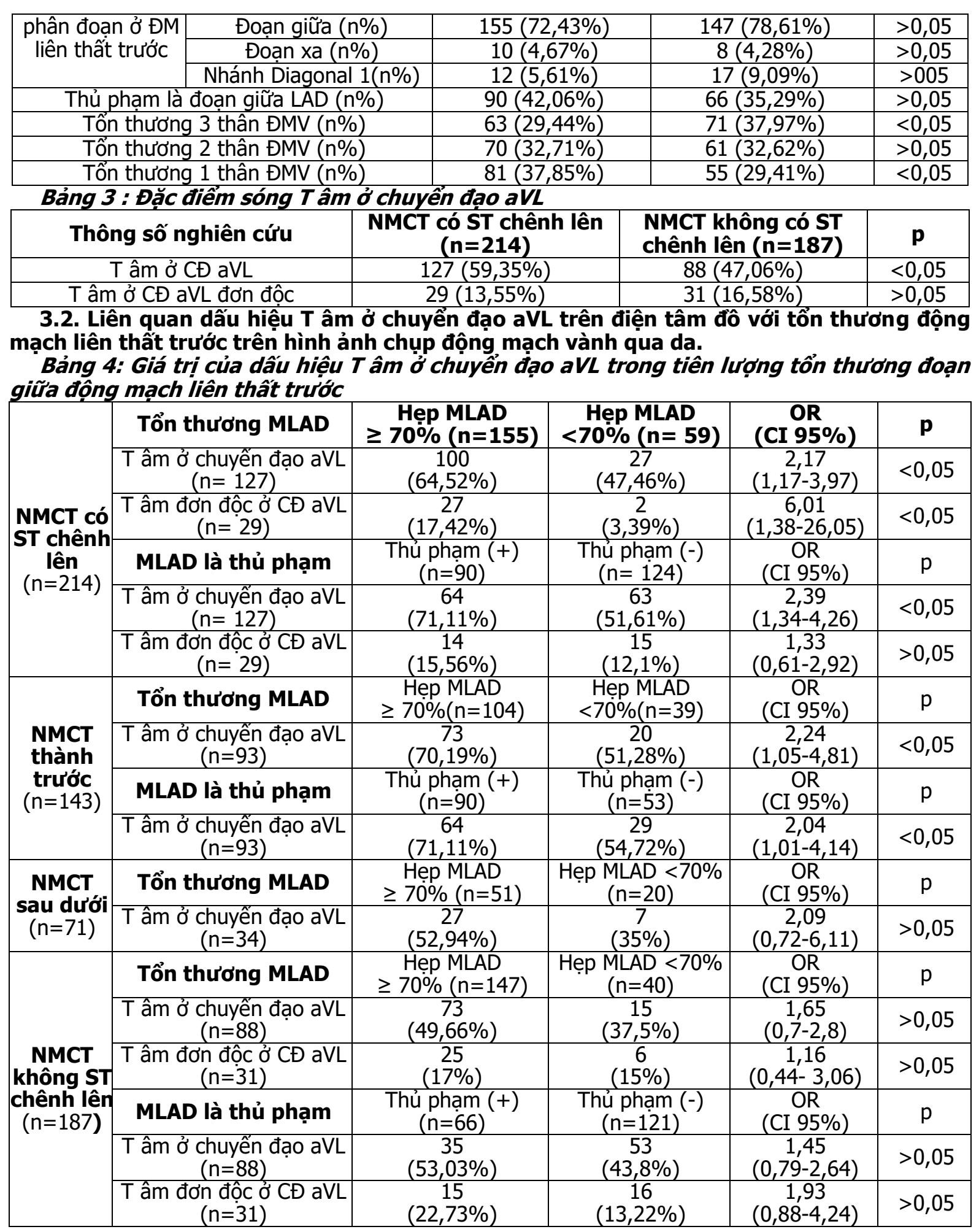

\section{Nhân xét:}

- Ở nhóm NMCT không ST chênh lên: không thấy có liên quan giữa dấu hiệu $T$ âm ở chuyển đạo aVL với tổn thương MLAD.
- Ở nhóm NMCT có ST chênh lên: Dấu hiêu T âm ở chuyển đạo aVL có liên quan và có giá trị dự báo tổn thương/ thủ phạm là MLAD (OR= $2,17$ và $2,39, p<0,05)$ với độ nhậy $64,5 \%$ và 
$71,1 \%$, độ đặc hiệu $54,2 \%$ và $49,2 \%$, giá trị dự báo dương tính $78,7 \%$ và $50,4 \%$, giá trị dự báo âm tính $36,8 \%$ và $70,1 \%$. Đặc biệt dấu hiệu $T$ âm đơn độc ở chuyển đạo $\mathrm{aVL}$, tuy hiếm gặp nhưng có giá trị dự báo tổn thương ( hẹp $\geq 70 \%$ ) MLAD với độ đặc hiệu cao 96,6\%

- Khi xét riếng nhóm NMCT thành trước :Dấu hiệu T âm ở chuyển đạo aVLcó giá trị dự báo tổn thương/thủ phạm là MLAD với độ nhậy $70,2 \%$ và $71,1 \%$, độ đặc hiệu $48,7 \%$ và $45,3 \%$, giá trị dự báo dương tính $78,5 \%$ và $68,8 \%$, giá trị dự báo âm tính $38 \%$ và $48 \%$. Ở nhóm NMCT thành sau không rõ mối liên quan giữa dấu hiệu $\mathrm{T}$ âm ở chuyển đạo $\mathrm{aVL}$ với tổn thương MLAD ( $\mathrm{OR}=2,09$ CI95\% $=0,72-6,11 ; p>0,05$ )

\section{BÀN LUÂ̂N}

Ởnhóm NMCT cấp có ST chênh lên có mối liên quan giữa dấu hiệu $\mathrm{T}$ âm ở chuyển đạo $\mathrm{aVL}$ với tổn thương MLAD $(\mathrm{OR}=2,17 ; \mathrm{CI}=1,17-3,97$, $\mathrm{p}<0,05)$. Ở nhóm NMCT không $\mathrm{ST}$ chênh lên không có mối liên quan trên $(O R=1,64 ; p>0,05)$.

Sóng $T$ âm trên điện tâm đồ rất quan trọng để chẩn đoán và phát hiện sớm các tổn thương do thiếu máu cục bộ và thường được ghi nhận sớm hơn dấu hiệu ST chênh lên ở bệnh nhẩn $\mathrm{HCVC}^{4}$. Cho đến nay đã có một số nghiên cứu tập trung vào giá trị chẩn đoán của dấu hiệu $T$ âm ở chuyển đạo $\mathrm{aVL}$ trong dự đoán tổn thương $M L A D^{2}, 3,5,6$. Nghiên cứu của Nakanishi và $c S$ (2016) trên 219 bệnh nhân HCVC cho thấy sóng $\mathrm{T}$ âm ở chuyển đạo $\mathrm{aVL}$ có độ nhạy thấp là $32,9 \%$ và độ đặc hiệu là $48,2 \%$ trong dự đoán tổn thương MLAD, dấu hiệu $T$ âm đơn độc ở chuyển đạo $\mathrm{aVL}$ có độ đặc hiệu 86,9\%trong dự báo tổn thương MLAD, các giá trị này thay đổi không đáng kể khi MLAD là ĐMV thủ phạm². Trong một nghiên cứu khác, sóng $\mathrm{T}$ âm ở chuyển đạo aVL có độ nhạy là $86,5 \%$ và độ đặc hiệu là $55,6 \%$ để dự đoán tổn thương MLAD ${ }^{5}$. Ở đối tượng bệnh nhân bệnh ĐMV ổn định mãn tính, OR của sóng $T$ âm ở chuyển đạo $a V L$ để dự đoán tổn thương MLAD là 2,933. Nghiên cứu của Tạ Quốc Huân (2019) trên 396 BN chẩn đoán bệnh động mạch vành ổn định được chụp động mạch vành qua da, dấu hiệu sóng $T$ âm ở chuyển đạo aVL thấy ở 197 BN (49,75\%), liên quan đến tổn thương đoạn giữa động mạch liên thất trước cao hơn nhóm không có T âm ở chuyển đạo $\mathrm{aVL}(\mathrm{OR}=4,348$ với khoảng tin cậy $95 \%)^{7}$. Tuy nhiên trong nghiên cứu của chúng tôi, ở nhóm NMCT có ST chênh lên dấu hiệu T âm ở chuyển đạo $\mathrm{aVL}$ có giá trị dự báo tổn thương/ thủ phạm là đoạn giữa động mạch liên thất trước với độ nhậy, giá trị dự báo dương tính lần lượt là $64,5 \%, 71,1 \%$ và $78,1 \%, 50 \%$; tuy nhiên độ đặc hiệu thấp $52,5 \%$ và $48,4 \%$. Tuy nhiên dấu hiệu $T$ âm đơn độc ở chuyển đạo $\mathrm{aVL}$ có giá trị dự báo tổn thương đoạn giữa động mạch liên thất trước với độ đặc hiệu cao là 98,2\%.

- Ở phân nhóm NMCT thành trước dấu hiệu T âm ở chuyển đạo $\mathrm{aVL}$ có giá trị dự báo tổn thương/ thủ phạm là MLAD với độ nhậy, giá trị dự báo dương tính lần lượt là $70,2 \% ; 71,1 \%$ và $77,7 \% ; 68,1 \%$. Ở phân nhóm NMCT thành sau, trước đây dấu hiệu $T$ âm ở chuyển đạo $\mathrm{aVL}$ thường được xem là dấu hiệu soi gương của ST chênh lên ở các chuyển đạo thành sau với tổn thương chủ yếu là ĐMV phải ${ }^{8}$. Trong nghiên cứu của chúng tôi ở nhóm NMCT thành sau bệnh nhân có dấu hiệu T âm ở chuyển đạo aVLcó tổn thương đoạn MLAD kèm theo nhiêu hơn so với không có $\mathrm{T}$ âm ở $\mathrm{aVL}$, tuy nhiên do cỡ mẫu nhỏ nên chưa thấy được mối liên quan này $(\mathrm{OR}=$ 2,09 CI95\% $=0,72-6,11 ; p>0,05$ )

\section{KẾT LUẬN}

Ở bệnh nhân NMCT có ST chênh lên, dấu hiệu $T$ âm ở chuyển đạo $a V L$ trên điện tâm đồ có liên quan và có giá trị dự báo vị trí tổn thương hoặc thủ phạm là MLAD. Ở nhóm NMCT không ST chênh chưa thãy liên quan giữa dấu hiệu $T$ âm ở chuyển đạo aVL với vị trí tổn thương hoặc thủ phạm là MLAD

\section{TÀI LIỆU THAM KHẢO}

1. Thygesen K, Alpert JS, Jaffe AS, et al. Third universal definition of myocardial infarction. European heart journal. 2012;33(20):2551-2567.

2. Nakanishi N, Goto T, Ikeda T, Kasai A. Does T wave inversion in lead aVL predict mid-segment left anterior descending lesions in acute coronary syndrome? A retrospective study. BMJ open. 2016;6(2):e010268.

3. Farhan HL, Hassan KS, Al-Belushi A, Sallam M, Al-Zakwani I. Diagnostic Value of Electrocardiographic T Wave Inversion in Lead aVL in Diagnosing Coronary Artery Disease in Patients with Chronic Stable Angina. Oman medical journal. 2010;25(2):124-7.

4. Kracoff $\mathrm{OH}$, Adelman AG, Oettinger $M$, et al. Reciprocal changes as the presenting electrocardiographic manifestation of acute myocardial ischemia. The American journal of cardiology. 1993;71(15):1359-62.

5. Hassen GW, Costea A, Smith T, et al. The neglected lead on electrocardiogram: $T$ wave inversion in lead $\mathrm{aVL}$, nonspecific finding or a sign for left anterior descending artery lesion? The Journal of emergency medicine. 2014;46(2):165-70.

6. Masood Ali Akbara, Imran Waheeda, Salman Munira và các cộng sự. A study of electrocardiographic $\mathrm{T}$ wave inversion in patients with tight mid left anterior descending artery 
stenosis. Original Article. 2014; 12(2):30-32.

7. Ta Quốc Huân và Nguyê̂n Thì Bach Yến. Mối liển quan giữa dấu hiêu $\mathrm{T}$ âm ở chuyển đao $\mathrm{aVL}$ trên điện tâm đồ với tổn thương động mạch liên thất trước trên hình ảnh chup động mach vành qua da ở bệnh nhân bệnh động mạch vành ổn định. Luận văn Thạc sỹ y học , Đại học Y Hà Nội. 2019;
8. Kracoff OH, Adelman AG, Marquis JF, Caspi A, Aldridge HE, Schwartz L. Twelve-lead electrocardiogram recording during percutaneous transluminal coronary angioplasty. Analysis of reciprocal changes. Journal of electrocardiology. $1990 ; 23(3): 191-8$.

\section{ĐĂC ĐIỂM LÂM SÀNG VÀ CÂN LÂM SÀNG CỦA BỆNH NHÂN NGộ ĐộC CẤP MộT SỐ THUỔC AN THẦN KINH THƯỜNG GẶP}

\section{TÓM TẮT}

Mục tiêu: Mô tả đặc điểm lâm sàng và cân lâm sàng của bệnh nhân ngộ độc cấp một số thuốc an thần kinh (ATK) thường gặp tại Trung tâm Chống độc Bệnh viện Bạch Mai. Phương pháp: Nghiên cứu mô tả tiến cứu trên 61 bệnh nhân ngộ độc cấp thuốc an thần kinh tại Trung tâm chống độc, Bênh viên Bach Mai từ tháng 1 năm 2020 tới tháng 6 năm 2021. Kết quả: Trong số bệnh nhân nghiên cứu, nữ chiếm $55,7 \%$, tuổi trung bình là 38,9 $\pm 18,6$ (15 - 81), nguyên nhân ngộ độc hay gặp nhất là tự tử $(88,5 \%)$. 68,8\% bệnh nhân ngộ độc nhóm ATK không điển hình nhiều hớn so với ngổ độc nhóm thuốc ATK điển hình (26,2\%). Đa số bệnh nhân nhập viện với triệu chứng nhe, trung bình $77,1 \%$, các triệu chứng lầm sàng thường gặp gồm giám ý thức $(37,7 \%)$, mạch nhanh $(42,6 \%)$, suy hô hấp $(23 \%)$ và đồng tứ co $(16,4 \%)$. Thay đổi điện tim hay gặp gồm nhịp nhanh xoang và QT kéo dài. Kết luân: nghiên cứu đã cho thấy các đặc điểm lâm sàng và cận lâm sàng chính của bệnh nhân ngộ độc cấp một số thuốc an thần kinh thường gặp.

Tư khóa: thuốc an thần kinh, ngộ độc cấp, đặc điểm lâm sàng và cận lâm sàng

\section{SUMMARY \\ CLINICAL FEATURES AND LABORATORY ABNORMALITIES OF SOME COMMON NEUROLEPTIC POISONINGS}

Objectives: to describe the clinical characteristics and laboratory features of patients with acute poisoning of some common neuroleptics at Vietnam Poison Control Center, Bach Mai Hospital. Methods: A prospective observational study included 61 patients poisoned by some common neuroleptics from January 2020 to October 2021. Results: Among the study patients, female accounted for $55.7 \%$, the mean age was $38.9 \pm 18.6(15-81)$ years old, the most common cause of poisoning was suicide ( $88.5 \%) .68 .8 \%$ of the patients were poisoned with atypical neuroleptics,

\footnotetext{
${ }^{1}$ Trường Đại học Y Hà Nội,

${ }^{2}$ Trung tâm Chống độc

Chịu trách nhiệm chính: Lưu Văn Hậu

Email: luuvanhau211@gmail.com

Ngày nhận bài: 18.8.2021

Ngày phản biên khoa hoc: 14.10.2021

Ngày duyệt bài: 21.10.2021
}

\section{Lưu Văn Hậu ${ }^{1}$, Đặng Thị Xuân²}

more common than typical group (26.2\%). Most of the patients were hospitalized with mild symptoms (77.1\%), common clinical symptoms include unconsciousness (37.7\%), tachycardia (42.6\%), respiratory failure (23). \%) and pupil constriction (16.4\%). Common electrocardiographic changes included sinus tachycardia and QTC prolongation. Conclusion: The study revealed the main clinical and laboratory characteristics of patients with acute poisoning of some common neuroleptics.

Keywords: neuroleptics, acute poisoning, clinical and laboratory characteristics

\section{I. ĐĂT VẤN ĐỀ}

Thuốc an thần kinh (ATK) hay thuốc chống loạn thân là nhóm thuốc được sử dụng rộng rãi trong điêu trị các rối loạn tâm thân bao gồm tâm thân phân liệt (TTPL), rối loạn cảm xúc lưỡng cực, các rối loạn trâm cảm nặng... Những năm trở lại đây, việc sử dụng thuốc ATK trong điều trị các bênh lý không do nguyên nhân tâm thân đang ngày càng gia tăng, bao gồm điều trị tình trạng nôn không đáp ứng với điều trị chống nôn thông thường, đau đâu, chóng mặt, hội chứng Tourette, và đau thân kinh liên sườn...1. Các thuốc ATK được chia thành hai nhóm: điển hình và không điển hình. Nhóm ATK điển hình bao gồm các thuốc như butyrophenon, dibenzoxapin, diphenylbutylpiperidin và phenothiazin. Nhóm không điển hình bao gồm các thuốc mới như bezopin, indol, quinolinon².

Ngộ độc thuốc ATK được chẩn đoán dựa vào tiên sử sử dụng thuốc, các hội chứng và triệu chứng lâm sàng bao gồm: giảm ý thức, hội chứng kháng cholinergic, hội chứng ngoại tháp, các triệu chứng trên hệ tim mạch, co giật vv. Bệnh nhân (BN) ngộ độc thuốc ATK nặng có thể hổn mê, tụt huyết áp, hội chứng QT kéo dài, xoắn đỉnh thậm chí rung thất, tử vong. Xét nghiệm đo nồng độ thuốc ATK trong huyết thanh không được sư dụng rộng rãi và không hữu ích trong điêu trị ngộ độc ATK, do đó việc khám lâm sàng đây đủ, chính xác đóng vai trò quan trọng 